\title{
Organizational Culture, Knowledge Sharing, and Intellectual Capital: Directions for Future Research
}

\author{
Mujid Marwan Attar \\ School of Professional Practice and Leadership, Faculty of Engineering and IT, University of Technology Sydney, New South Wales, \\ Australia \\ Email address: \\ MujidMarwanO.Attar@student.uts.edu.au \\ To cite this article: \\ Mujid Marwan Attar. Organizational Culture, Knowledge Sharing, and Intellectual Capital: Directions for Future Research. International \\ Journal of Business and Economics Research. Vol. 9, No. 1, 2020, pp. 11-20. doi: 10.11648/j.ijber.20200901.12
}

Received: October 16, 2019; Accepted: January 2, 2020; Published: January 27, 2020

\begin{abstract}
Organizational culture and knowledge sharing are two significant factors for the long-term success of an organization. As the sum of all knowledge used to develop a business and gain competitive advantage, intellectual capital is a mechanism for organizational performance. Despite that, existing evidence recounts the individual role of knowledge sharing on the organization's intellectual capital; there is a lack of exploration and explanation of the role of organizational culture, knowledge sharing environment, and intellectual capital. This paper presents a conceptual model on the relationship between organizational culture, knowledge sharing practices (i.e. knowledge types, knowledge sharing approaches and knowledge sharing processes), and organization performance. The model proposes the potential measures of an organisation's knowledge sharing environment and the role of organisational culture in shaping knowledge sharing practices and intellectual capital development and utilisation. Hypothetically, we argue that organisation culture is positively related to the organisation's knowledge sharing environment, which in turn is positively related to its intellectual capital. On the other hand, we propose that organisational culture is positively related to intellectual capital. This paper indicates directions for further research and discusses the potential implications for theory and practice on knowledge management.
\end{abstract}

Keywords: Organisational Culture, Knowledge Sharing, Intellectual Capital, Organization Success

\section{Introduction}

Knowledge is a key factor for ensuring protracted sustainability of an organization [1]. Knowledge management in an organization involves various activities or processes [2], such as knowledge creation, storing, sharing and applications. Knowledge sharing is the most significant knowledge process that paves way for other knowledge processes to be effected. The most important aspect is that knowledge sharing paves way for intellectual capital development and utilization [3, 4]. In fact knowledge sharing and intellectual capital complement one another [5] to enable improved performance and organizational success [3]. Existing literature explores knowledge sharing, holistically without articulating the most crucial aspects of knowledge sharing that facilitate intellectual capital. This study extends existing literature by proposing that explore knowledge sharing practices (i.e. type of knowledge, knowledge sharing strategy and knowledge sharing process) as crucial elements in the development of intellectual capital of an organization.

Culture is a basic element to knowledge management [6]. Therefore, a number of the researchers believe that the organizational culture is the chief facet, which dominates the knowledge-sharing efficacy within the organization [7, 8]. Organization culture encourages employees to create and share knowledge within an organization [7]. For this reasons, organizations should establish an appropriate culture sufficient for knowledge management because organizational culture influences how an organization adopts knowledge management initiatives [8]. Organization culture and knowledge management infrastructure may foster organization success [8]. Moreover, the success or failure of organization depends upon its culture [9]. Both financial and non-financial benefits are connected with organization success-i.e. operational performance and financial performance [3]. Furthermore, intellectual capital (such as human, structural and relational capital) drives the value of an organization in terms of financial and non-financial 
performance [3-5].

Despite the growing number of studies relating on organization culture and knowledge management, there is insufficient understanding on how an organization can improve its performance through organizational culture, multiple knowledge sharing practices and intellectual capital. Moreover, the combination of organization culture, knowledge sharing and intellectual capital is of great importance in the development of a knowledge-based organization. This study develops a conceptual framework of organizational culture, knowledge sharing practices and intellectual capital for organizational success. This research attempts to address the following research question: What impacts do organization culture has on knowledge sharing dimensions towards organization success? Is the effect of knowledge sharing aspects on organization performance mediated by intellectual capital?

\section{Theoretical Background}

\subsection{Organisational Culture}

Organizational culture, according to Schein [9], is a pattern of shared basic assumptions that the group learned as it solved its problems of external adaptation and internal integration that has worked well enough to be considered valid and, therefore, to be taught to new members as the correct way to perceive, think, and feel in relation to those problems. Organizational culture is out-rightly considered as the most fundamental and constant strength within any business and is associated with sustainability [9]. Culture is also a significant division that cultivates an active organization [9]. Organizational culture is one of the most critical factors, which control the company's capability, efficacy, endurance and success. Leadership plays a vital and significant role in maintaining and retaining the organizational culture. Organizational culture is based on the mutual trust, profound communication and IT support provided by one team or individual to another [9].

\subsubsection{Trust}

Trust is an entity's 'willingness to be vulnerable to the actions of another' [10]. Trust embodies the beliefs about the anticipated behavior and intensions of the involved entities [10]. The concept of trust is deep rooted in the culture theories such as [9]. Subsequent studies on trust, c.f. [11], have operationalized trust into various of types, most important of which is interpersonal trust $[12,13]$.

Trust is a social reality [14]. To foster an organisation culture sufficient for knowledge sharing, organisations will have to recognise the role of trust among employees. Existing evidence suggests that trust will influence knowledge sharing and creation [15]. Such a view of trust relates closes to interpersonal trust which is the extent to which employees rely on each other to pursue their duties [12, 13]. Interpersonal trust is the pivot of social systems, and is governed by affect based, cognitive based trust $[14,16]$ and behavioural trust [14].

\subsubsection{Technology Support}

The role of organisational culture not only raises the issue of trust among employees and department. Different cultures may require different technologies to support communication and sharing [17]. The issue of technology support then becomes an important element of consideration in organisational culture. IT support, in the sense of this study, relates to the ability of organisations is to develop an IT environment sufficient to facilitate its knowledge management practices and utilisation of intellectual capital. IT support is an enabler for task organisation and innovation for improved team performance [18]. IT support for knowledge management indirectly affects organisational performance depending on the organisation's set of dynamic capabilities [19].

Organisational strategies towards IT support seek to overcome IT shortfall and IT underutilization [20]. Basing on Reynolds and Yetton [20] we can say that IT shortfall occurs when the organisation's IT infrastructure cannot fully support its knowledge management practices and utilisation of intellectual capital. IT underutilization, on the other hand, occurs when the organisations spends more on its IT infrastructure than that which is need to support its knowledge management practices and utilisation of intellectual capital.

IT support is directly related to expertise of the individuals and teams, there must be an atmosphere of mutual cooperation thus the expertise are shared among the workers ensuring prosperity and progress for the organization [21]. There are four aspect of IT support that facilitate knowledge sharing - i.e. task coordination, external connectivity, distributed cognition and interactivity [22].

\subsubsection{Communication}

An act of communication involves the transmission of messages between a sender and a receiver. There about three issues crucial in the communication processes - i.e. the communication style adopted by sender, the communication media or technology used to facilitate communication and the ability of the receiver to interpret the message. There two communication styles, which managers may have to assess in order to determine the most effective style in different contexts-i.e. one-way communication and two-way communication [23].

One-way communication is a unidirectional communication style in which the sender chooses what to communicate, decodes a message, and transmits a message. The receiver decodes the message and concedes the message. In contrast, a two-way communication is bidirectional communication where the receiver not only concedes but also reacts to the message and choses what to communicate as feedback and the cycle continues. The notable differences between the two communication styles is that in one way communication; no feedback is expected, the sender exercises control and the receiver is quite submissive to the sender. Whereas in a two-way communication, feedback is valued and therefore expected and accepted, the sender and 
receiver feel quite competent to communicate back and forth, so the sender does not over rule the receiver.

Culture influences the communication style and the interpretation of the message during communication [23]. The richness of the organisation's communication media, approaches and/or systems, on the other hand are also shaped by the cultural background of the organisation, which ultimately affects knowledge sharing [17]. Good communication practices increase trust within members of an organisation [22]. Communication is a core driver for employee commitment to organisational activities [24] and employee engagement consequently resulting in employee performance and organisational performance [25]. Furthermore, explicit communication norms are essential for effective use of IT support [22]

\subsection{Knowledge Sharing Practices}

Knowledge sharing within the organisation is often considered to represent a crucial aspect affecting the overall performance of the company [26]. Knowledge sharing enables employees to increase their working skills (Bock et al. 2005). Knowledge sharing creates a social context for individuals to create valuable knowledge contents that enhance the production of organisational intellectual property capital and growth [27].

Knowledge sharing is supported by acceptance of change, innovation, trust, communication, collaboration and IT support, teamwork, etc. (organisational culture) and will be correlated with factors like types, processes and procedures of sharing knowledge to understand their impact [3]. Effective knowledge sharing requires a consideration of a number of aspects; (1) knowledge sharing types, (knowledge sharing approaches, and knowledge sharing processes) [28].

\subsubsection{Knowledge Sharing Types}

Knowledge is broadly categorised into tacit and explicit knowledge [2, 29-31]. Knowledge can therefore be shared as tacit or explicit [3]. Tacit knowledge can be technical tacit or cognitive tacit, distinguished by the degree of tacitness [32]. The degree of tacitness is the level at which tacit knowledge is articulable for sharing among interacting individuals [32]. Technical tacit knowledge is an individual's personal skills and artisanship. Technical tacit knowledge evolves around one's practical knowledge that allows people to articulate such knowledge to an extent that makes it sharable. Cognitive tacit knowledge is an individual's beliefs, values and viewpoints, which are often, expressed the way an individual interprets their environment. Cognitive tacit emerges almost naturally and this makes inarticulable and hard to share among individuals.

Earlier studies [27, 29, 30] emphasise that tacit knowledge is difficult to transfer, and that face-to-face interaction may be the only means through which individuals will share such knowledge, although insufficiently. Later studies [2, 33, 34] show that some dimensions of tacit knowledge are articulable and therefore allow it to be transferred, even through socialisation technologies such as social media.
'Comparing tacit and explicit types of knowledge, is a way to think, not point out differences' [31]. Explicit knowledge refers to structured and formalised instances of knowledge. It is knowledge that individuals can described in formal language, print or electronic media, often based on established work processes, use people-to-documents approach [31]. Knowledge sharing and creation begins with tacit knowledge through socialization [33]. Ultimately explicit knowledge is created through codification in databases and information retrieval systems [31].

\subsubsection{Knowledge Sharing Approaches}

To a design sufficient knowledge sharing environment, organisations will have to recognize two approaches to knowledge sharing - codification and personalization [35], i.e. the commodity view of knowledge and the community view of knowledge respectively [36]. Knowledge intensive organisations should pursue either codification or personalization as a dominant knowledge sharing procedure or strategy [35].

Knowledge codification is the process through which 'knowledge is carefully codified and stored in databases, where it can be accessed and used easily by anyone in the company' [35].. It is 'the process of conversion of knowledge into messages that can be processed as information' [37], hence 'the process of transforming knowledge into information' [38]. This process aims to formalizing knowledge into appropriate codes, structures or schemes. Adopting a codification approach implies that the core focus of the organisation is to collect and organize knowledge [36]. This approach is recognized for reducing costs of knowledge acquisition and improving reliability of knowledge storage and recall [37].

Social constructivists suggest that knowledge is a social artefact produced through shared understandings emerging due socialisation and interaction [6]. Socialisation and interaction between individuals in the organisation are the premise of the personalization approach. Personalization is person-to-person exchange and creation of knowledge, which Nonaka and Toyama [33]) refer to as socialisation. Personalization develops a rich medium for communication, which is related to the use of people's contrivance for knowledge sharing [39]. Since individuals are considered the main carriers of knowledge they are able to rearrange information in order to apply it in a new setting (Allen, 1977) The individuals are custodians of knowledge and could transfer it to one another [40]. That is why personalization is considered as a knowledge sharing mechanism that has the flexibility and tool to transfer tacit knowledge and allow the discussion and the sharing of this knowledge in order to develop what is called "new knowledge" [38].

\subsubsection{Knowledge Sharing Processes}

The process of knowledge sharing is explicated in extant literature as central in organisational intellectual capital development [41, 42] and organisational learning [39]. Knowledge sharing is the activity of transferring knowledge in various forms of one person, group or organisation to 
another (McAdam et al., 2012). It is 'the process where individuals exchange their (tacit or explicit) knowledge and jointly create new knowledge in a knowing process within a social context that is also constructed out of these activities' [43]. A knowledge sharing process will consists of two dimensions-knowledge donating and knowledge collecting [44, 45].

Knowledge donation is also represented as knowledge contribution in other studies such as [44, 46]. Knowledge donation is the processes of 'communicating to others one's intellectual capital' [46]. The nature of knowledge donation in any organisational setting is a significant factor of knowledge management where knowledge is needed and can be used. During knowledge donation, the donors dedicate their valuable time to record and post their codified knowledge, skills and experiences on the share media for others to receive and reconstruct the knowledge to foster action. Therefore, communication processes and information flows are fundamentally a major driver for knowledge donation in organisations.

Given the duality of the knowledge sharing processes [47], collecting, seeking or receiving knowledge are core process that must occur for knowledge donation to be relevant. We must remember that knowledge sharing is 'a relational act based on a sender-receiver relationship that incorporates communicating one's knowledge to others as well as receiving others' knowledge' [48]. Knowledge sharing is also achieved through knowledge collection which involves consulting others to access their intellectual capital [46]. The knowledge collector accesses others' codified knowledge or narratives available on the share media.

Knowledge collection involves activities like searching or locating knowledge repositories and knowledge contributors. It also involves efforts to connect and extract require knowledge from knowledge contributors linked on the same network. Knowledge seekers normally seek to address an immediate or future knowledge requirement to support a certain task.

\subsection{Intellectual Capital}

The sum of all knowledge for gaining competitive advantage is intellectual capital [3]. The term 'intellectual capital' is analogous for knowledge assets [49]. Intellectual capital is a two-level concept, such as human capital (knowledge created by and stored in a firm's employees-human resource) and structural capital (the embodiment, empowerment, and supportive infrastructure of human capital) [49]. There three major components of intellectual capital - i.e. human capital, structural capital, and relational capital $[3,50]$.

\subsubsection{Human Capital}

Human capital is 'an organisation's combined human capability for solving business problems. [It] is inherent in people and cannot be owned by organizations' [50]. One may as well say it is 'the intelligence of the organisational members' [51] or the cumulative knowledge of, skill, and experience of the organisation's employees or managers' [52].
Therefore, employee development and enabling knowledge sharing in the organisation are key drivers for development of human capital and value creation for an organisation [53]. Organisations must carefully assess, evaluate and consider their human capital as an important aspect of intellectual capital because it is a powerful resource that supports innovation and strategic renewal [51]. Human capital is measured as the knowledge, competences and technical skills owned by the employees.

\subsubsection{Structural Capital}

Structural capital is 'the mechanisms and structures of the organization that can help support employees in their quest for optimum intellectual performance and therefore overall business performance' [51]. According to Chatzkel [52] it is 'the embodiment, empowerment and supportive infrastructure of human capital'. This form of intellectual capital is everything in an organisation that supports employees in their work ... such as buildings, hardware, software, processes, patents, and trademarks.' Structural capital is relatively broad as compared to other forms of capital, and encompasses three aspects as a way to organisational performance $[52,54]$ - i.e. organisational capital, innovation capital and process capital.

An organisation with strong structural capital will have a supportive culture that allows individuals to try things, to fail, to learn, and to try again, supporting the contribution that the single employees can give to the company [51]. Structural capital allows human capital to develop and grow inside the company. Structural capital is represented by the knowledge contained in the procedures and in the organisational routines used by the employee, consciously or not, during the carrying out of a task [51, 54].

\subsubsection{Relational Capital}

Relational capital, also known as customer capital, 'is the potential for capitalizing on good customer relationships as well as external business networks' [55]. Such business networks include relationships with clients, suppliers and partners [55]. According, relational capital is particularly the knowledge of an organisation's marketing channels and customer relationships [51] as well as industry and government associations [52]. It is important to that relational capital is not just the business networks, but the strength and loyalty embedded in those networks [50].

Relational capital is built by a process of repeated exchange between the organisation and its external connections in order to generate new ideas, perspectives and feedback on products and/or services [52]. Relational capital will thus relate closely to attributes such as trust [56]. Relational capital is measured by the enduring relationship between the organisation and its clients.

Human, structural and relational capital offers a powerful approach to differentiating organisational financial and nonfinancial performance [3]. Therefore, organisations incorporating all aspects intellectual capital in their overall business strategies will improve the way they share knowledge, and will also gain a better position to improved 
operational and financial performance [3].

\section{Research Model and Hypotheses}

The model in Figure 1 is based on existing literature on organisation culture and knowledge sharing. Organisational culture is based on Gupta and Govindarajan [57] and AlAlawi, Al-Marzooqi [58]. Knowledge sharing dimensions are adopted from [27, 35, 45]. Intellectual capital and organisation success were adopted from Wang, Wang [3]. Figure 1 shows the research model and Table 1 shows the description of all factors included in the model.

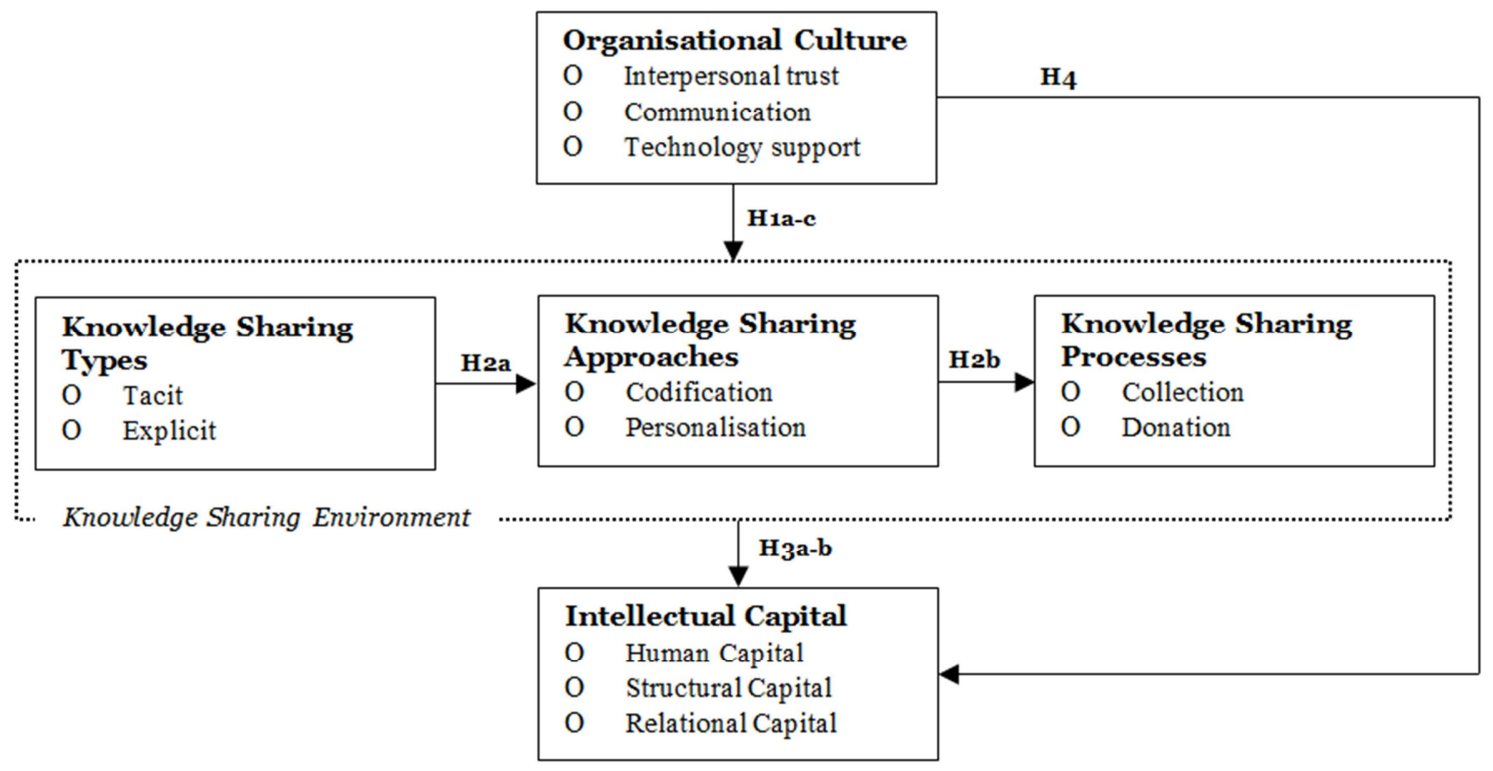

Figure 1. Research Model.

The key areas of focus presented in Figure 1 above are defined and summarised in Table 1 below. These areas of focus include - organisation culture, knowledge sharing, intellectual capital and organisation success. The knowledge sharing involves three critical aspects - i.e. knowledge types $[3,29,30]$, knowledge management strategies / approaches [35] and knowledge sharing processes [1, 44, 45].

Table 1. Definition of Factors.

\begin{tabular}{|c|c|c|c|}
\hline Factor & & Description & Source \\
\hline \multicolumn{2}{|l|}{ Organisational Culture } & $\begin{array}{l}\text { Communication. "Communication here refers to human interaction through oral } \\
\text { conversations and the use of body language while communicating". } \\
\text { Trust: refers to "co-workers having a good level of faith in each other in terms of } \\
\text { intentions and behaviours." } \\
\text { IT support: refers to the "level to which facilitating knowledge-sharing through } \\
\text { information technology use." }\end{array}$ & {$[58]$} \\
\hline \multirow{3}{*}{$\begin{array}{l}\text { Knowledge sharing } \\
\text { environment }\end{array}$} & $\begin{array}{l}\text { Knowledge Sharing } \\
\text { Types }\end{array}$ & $\begin{array}{l}\text { Explicit knowledge is knowledge that can exist in symbolic or written form. } \\
\text { Tacit knowledge is often context dependent and personal in nature. It is hard to } \\
\text { communicate and deeply rooted in action, commitment, and involvement }\end{array}$ & {$[3,29,30]$} \\
\hline & $\begin{array}{l}\text { Knowledge sharing } \\
\text { approaches }\end{array}$ & $\begin{array}{l}\text { Codification: Knowledge is captured and stored in electronic repositories / databases, } \\
\text { independent of the individual that generated knowledge. } \\
\text { Personalization: Knowledge can be shared through person to person interaction or through } \\
\text { some communication channel. }\end{array}$ & {$[35]$} \\
\hline & $\begin{array}{l}\text { Knowledge sharing } \\
\text { process }\end{array}$ & $\begin{array}{l}\text { Knowledge donating is defined as "the process of individuals communicating their } \\
\text { personal intellectual capital to others" while, } \\
\text { Knowledge collecting is defined as the "process of consulting colleagues to encourage } \\
\text { them to share their intellectual capital." }\end{array}$ & {$[1,44,45]$} \\
\hline \multirow[b]{2}{*}{ Intellectual capital } & & $\begin{array}{l}\text { Intellectual capital "is the sum of all knowledge and knowing capabilities that will be } \\
\text { crucial for firms to gain a sustainable competitive advantage". } \\
\text { Human capital "is the sum of employees "competence, knowledge, skills, innovativeness, } \\
\text { attitude, commitment, wisdom, and experience". }\end{array}$ & \\
\hline & & $\begin{array}{l}\text { Structural capital is described as "the valuable strategic assets of organisational } \\
\text { capabilities, organisational culture, routines, procedures, information systems, hardware, } \\
\text { software, databases, company images, patents, copyrights, trademarks, and so on". } \\
\text { Relational capital "the knowledge and learning capabilities that exist in relationships } \\
\text { between an organisation and its external stakeholders". }\end{array}$ & {$[3,59]$} \\
\hline
\end{tabular}


Relationship between organisational culture and the organisation's knowledge environment-Organizational culture influences knowledge sharing, where, information systems, organizational structure, and communications among staff, reward system, and trust are positively related to knowledge sharing in organizations [58]. It is also important to note that knowledge sharing is a fundamental process for developing organizational intellectual capital and may affect both operational and financial success $[3,5]$. Knowledge sharing practices improve organizational performance through the development of human capital, structural capital, and relational capital $[3,4]$.

H1 a-c: There is a positive relationship between organisational culture and knowledge sharing types, knowledge sharing approaches and knowledge sharing processes.

Relationship between knowledge sharing types and knowledge sharing approaches - Knowledge and information spread in an organisation on need to know basis. The knowledge is also classified, some information is explicit and shared with all the employees but some are tacit which is required to keep to a certain sphere for better working of organisation [60]. Method/approaches used for sharing also differ in mechanics and procedures, personalization and codifications are techniques, which utilized to safeguard the knowledge thus ensuring it to be proliferation free [61]. Although knowledge sharing literature rarely established the differences between sharing tacit and/or explicit knowledge, some scholars [3, 45] recognise the importance of exploring the role of different types of knowledge in an organisation's knowledge processes. Additionally, a few studies explore the role of knowledge sharing approaches. It is important to recognise that personalisation approach is closely associated with tacit knowledge while codification is an approach for explicit knowledge sharing [34, 62]. According to Wyatt [62]), codification is a people to document approach sufficient for explicit knowledge management, while the personalisation approach is a people to people approach sufficient for enabling tacit knowledge sharing and transfer. In other cases, we may find that personalisation makes it easy for employees to share knowledge, employees are able to understand the usefulness of knowledge and improves their satisfaction with knowledge sharing systems of the organisation [63].

$\mathrm{H} 2 \mathrm{a}$ : There is a positive relationship between knowledge sharing types and knowledge sharing approaches of an organization.

Relationship between knowledge sharing approaches and knowledge sharing process - Most of the organisations use personalization and codification techniques to personally either disseminate essentials or if not possible disseminate it through coding which is previously decided. When individuals donate and collect knowledge through knowledge repositories such as databases, then the organisation's knowledge sharing approach or strategy is codification [35]. The information and knowledge is then classified and categorized to ensure only authorized access [64]. On the other hand, when individuals donate and collect knowledge through person-to-person interaction, then the organisation's knowledge sharing approach is personalisation [35]. The organisation thus allows individuals to work through communities and interaction to access knowledge, i.e. a community view of knowledge [36].

According to Huysman and De Wit [65]) personalisation strategy may overcome the knowledge sharing challenges encountered through codification strategy. In fact social technologies offer a sufficient context and ease to use platform for effortless knowledge donation and collection through person-to-person interaction [66]. Organisation may have to consider the fact that people are the single most important factor in knowledge management [6]. Personalisation allows individuals to establish ties which are crucial for tacit knowledge sharing [36]. Personalisation may enable knowledge sharing more than codification approach, when the firm intends to foster creativity through channelling individual expertise [35]. Codification may enable knowledge sharing more than personalisation approach, when the firm intends to foster high-quality and reliable reuse of knowledge [35]. Therefore, managers ought to be aware that the knowledge sharing approaches define the organisation's knowledge sharing processes, and are closely related to the organisation's overall business strategy [35].

$\mathrm{H} 2$ b: There is a positive relationship between knowledge sharing approaches and knowledge sharing process

Relationship between knowledge environment and intellectual capital - Knowledge sharing is essential intellectual capital development $[67,68]$. Knowledge sharing not only refers to the knowledge sharing processes collection and donation - in an organisation, but also constitutes the organisation's knowledge sharing approaches and the type of knowledge shared widely across the organisation. In fact, there is a positive relationship between the knowledge sharing practices and intellectual capital [3, 69, 70]. Consequently, intellectual capital development enables the firm to perform better, especially when its knowledge management approaches are well developed [3, 67]. Knowledge sharing practices improve organisational performance through the development of human capital [69], structural capital [70], and human capital [71].

Both tacit and explicit knowledge is very crucial in the development and utilisation of intellectual capital [3]. In fact for one to understand the organisation's intellectual capital, they need a clear understanding of the organisation's knowledge [72]. While some studies [3] indicate that tacit knowledge is the most significant resource for intellectual capital development, others [73] indicate that both types of knowledge are relatively crucial in the development of intellectual capital.

Personalization and codification techniques must be selected as knowledge management strategies in order to ensure that the information and knowledge can reach to the person it meant for [74]. 'There is a relationship between the degree of codification of knowledge and the amount of value it can be said to command' [72]. Further still, the 
personalisation approach influences ease of use, usefulness and user satisfaction of knowledge and knowledge management systems in the organisation [63]. Ease of use and usefulness of knowledge are crucial for enabling valuable knowledge. Intellectual capita being the 'knowledge that can be converted into value' [72]. To improve organisational performance and value creation, there has to be a fit between the organisation's intellectual capital and knowledge management strategy [42].

Researchers and practioners have to realise that the integration of intellectual capital and knowledge management requires alignment of knowledge management processes with intellectual capital assets to meet the organisation's strategic needs' [68]. There is evidence that some knowledge processes, such as knowledge creation process influences organisational performance through the mediating effect of intellectual capital [75]. We must realise that knowledge sharing is a constitutive part of the organisation's knowledge creation process. Consequently, knowledge-sharing processes work hand in hand with the organisation's intellectual capital to reach organisation objectives. For instance, intellectual capital will affect the knowledge sharing behaviour in an organisation [76]. Knowledge sharing behaviour may range from knowledge donation, knowledge collection, and quality of knowledge shared or the quantity of knowledge shared among individuals. Knowledge sharing processes tend to influence the organisation's innovation capability and performance [77].

H3 a-b: There is a positive relationship between the knowledge-sharing environment (i.e., knowledge sharing types, knowledge sharing approaches, and knowledge sharing process) and intellectual capital.

Relationship between organisational culture and intellectual capital - Use of modern technology, innovative methods and techniques in line with desired structure and relational alterations are the ways to remain compatible in this fast moving and competitive world [78]. Companies need to develop new strategies and policies incorporating new trends to ensure profitability and reliability. Company management has to specifically weigh his options and employ best possible information technology and operational model facilitating their ultimate motive. The structure is so developed that it should facilitate teamwork and desired results can only be achieved when people work together to achieve a common goal facilitated by structural and procedural domains [79].

Practitioners and researchers may not sufficiently articulate the guidelines towards intellectual capital development and utilisation without addressing cultural issues embedded in the environments where the organisations operate [80]. Organisational culture is a constitutive element of intellectual capital especially structural capital [81, 82]. In fact 'culture as the central nucleus around which the remaining integrated capitals configure' [82]. An organisational culture that will support intellectual capital development and utilisation includes the level of cultural homogeneity, or level of coherence, acceptance and general commitment to cultural values, business philosophy and ethics, social climate, or managerial commitment towards some concrete cultural values and attitudes' [81]. Such cultural aspects plus the national culture in the country where the organisation is established will affect the implementation and management of intellectual capital [83, 84].

Consequently, practitioners and researchers ought to remember that intellectual capital is best analysed depending on context [85], because the perception and operationalisation of knowledge and intellectual capital in the western countries cannot be directly transferred to nonwestern countries [86]. For example, a country like Saudi Arabia, with high power distance, high uncertainty avoidance and collectivism, may have lower levels of intellectual capital development [84]. Nonetheless, even the understanding of knowledge and intellectual capital in western countries is different from that of Asian countries [86].

H4: There is a positive relationship between organisational culture and intellectual capital.

\section{Discussion}

The input of organisational culture and the knowledge sharing practices (knowledge sharing types, knowledge sharing approaches, and knowledge sharing process) and intellectual capital in firms will be of great significance towards the organisational success. First, knowledge be it explicit or tacit is crucial for organisational success. Second, knowledge sharing approaches such as codification and personalization support knowledge sharing among individuals. Third, knowledge sharing process consists of collection and donation of knowledge. This paper suggests that knowledge types, knowledge sharing strategies and knowledge sharing processes affect the intellectual capital of the organisation i.e. (human capital, structural capital, and relational capital), which in turn could affect the organisation's success. Organisational culture is considered as a critical factor for knowledge sharing. This paper further contends that knowledge types, knowledge sharing strategies and knowledge sharing processes may posit direct influences on organisational success. The findings of this study will help organisations to recognize, plan and apply the sufficient knowledge sharing practices and organisational culture. In addition, the findings of this study will become of great significance in guiding firms towards organisational success.

\section{Conclusion}

This paper proposed a study to examine the effect of organisation culture and knowledge sharing environment on the firm's intellectual capital. Organisation culture is relates to interpersonal trust among employees, management support for IT, and the communication styles adopted by the organisation. We argued that such aspects of organisation culture will positively affect the orgaisation's knowledge 
sharing environment which includes three interreleated aspects - i.e., knowedge types, knowledge sharing processes and knowledge sharing approaches. We also argue that organisation culture and knowledge sharing environment all taken together will positively affect the firm's intellectual capital development and utilisation.

\section{References}

[1] Al Othman, F. A. and O. Sohaib, Enhancing Innovative Capability and Sustainability of Saudi Firms. Sustainability, 2016. 8 (12): p. 1229.

[2] Alavi, M. and D. E. Leidner, Knowledge management and knowledge management systems: Conceptual foundations and research issues. MIS quarterly, 2001: p. 107-136.

[3] Wang, Z., N. Wang, and H. Liang, Knowledge sharing, intellectual capital and firm performance. Management decision, 2014. 52 (2): p. 230-258.

[4] Hussinki, H., et al., Intellectual capital, knowledge management practices and firm performance. Journal of Intellectual Capital, 2017. 18 (4): p. 904-922.

[5] Hsu, I. and R. Sabherwal, Relationship between intellectual capital and knowledge management: an empirical investigation. Decision Sciences, 2012. 43 (3): p. 489-524.

[6] Dalkir, K., Knowledge Management in Theory and Practice. 2011, Cambridge, Mass., UNITED STATES: MIT Press.

[7] Al-Adaileh, R. M. and M. S. Al-Atawi, Organizational culture impact on knowledge exchange: Saudi Telecom context. Journal of knowledge Management, 2011. 15 (2): p. 212-230.

[8] Al Saifi, S. A., Positioning organisational culture in knowledge management research. Journal of Knowledge Management, 2015. 19 (2): p. 164-189.

[9] Schein, E. H., Organizational culture and leadership. Vol. 2. 2010: John Wiley \& Sons.

[10] Johnson, J. L. and J. B. Cullen, Trust in Cross-Cultural Relationships, in The Blackwell Handbook of Cross-Cultural Management, M. J. Gannon and K. L. Newman, Editors. 2002, Blackwell: Oxford UK. p. 335-360.

[11] Kang, K. and O. Sohaib, Individualistic-Collectivistic Impact on iTrust towards Purchase Intention in B2C E-Business. Journal of Internet and eBusiness Studies, 2016.

[12] Leimeister, J. M., W. Ebner, and H. Krcmar, Design, implementation, and evaluation of trust-supporting components in virtual communities for patients. Journal of Management Information Systems, 2005. 21 (4): p. 101-131.

[13] Paul, D. L. and R. R. McDaniel Jr, A field study of the effect of interpersonal trust on virtual collaborative relationship performance. MIS quarterly, 2004: p. 183-227.

[14] Lewis, J. D. and A. Weigert, Trust as a social reality. Social forces, 1985. 63 (4): p. 967-985.

[15] Kivrak, S., et al., Impact of national culture on knowledge sharing in international construction projects. Canadian Journal of Civil Engineering, 2014. 41 (7): p. 642-649.

[16] McAllister, D. J., Affect-and cognition-based trust as foundations for interpersonal cooperation in organizations. Academy of management journal, 1995. 38 (1): p. 24-59.

[17] Klitmøller, A. and J. Lauring, When global virtual teams share knowledge: Media richness, cultural difference and language commonality. Journal of World Business, 2013. 48 (3): p. 398406.

[18] Seeber, I., G. Waldhart, and R. Maier, IT Enablers for Task Organization and Innovation Support to drive Team Performance. 2014.

[19] Wang, E., G. Klein, and J. J. Jiang, IT support in manufacturing firms for a knowledge management dynamic capability link to performance. International journal of production research, 2007. 45 (11): p. 2419-2434.

[20] Reynolds, P. and P. Yetton, Aligning business and IT strategies in multi-business organizations. Journal of Information Technology, 2015. 30 (2): p. 101-118.

[21] Quink, U., An exploration of knowledge management and intellectual capital in a nonprofit organisation context. 2008, Queensland University of Technology.

[22] Malhotra, A. and A. Majchrzak, Enabling knowledge creation in far-flung teams: best practices for IT support and knowledge sharing. Journal of knowledge Management, 2004. 8 (4): p. $75-88$.

[23] Mead, R. and C. J. Jones, Cross-Cultural Communication, in The Blackwell Handbook of Cross-Cultural Management, M. J. Gannon and K. L. Newman, Editors. 2002, Blackwell: Oxford UK. p. 283-291.

[24] Femi, A. F., The Impact of Communication on Workers' Performance in Selected Organisations in Lagos State, Nigeria. IOSR Journal of Humanities and Social Science, 2014. 19 (8): p. $75-82$.

[25] Bedarkar, M. and D. Pandita, A study on the drivers of employee engagement impacting employee performance. Procedia-Social and Behavioral Sciences, 2014. 133: p. 106115.

[26] Boehm, E., Improving Efficiency and Effectiveness in an Automotive R\&D Organization. Research-Technology Management, 2012. 55 (2): p. 18-25.

[27] Nonaka, I. and N. Konno, The concept of" ba": Building a foundation for knowledge creation. California management review, 1998. 40 (3): p. 40-54.

[28] Attar, M. M. and K. Kang, The Effect of Organisational Culture and Knowledge Environment on Organisational Success: Directions for Future Research.

[29] Nonaka, I., The Knowledge-Creating Company. Harvard Business Review, 1991. 69 (6): p. 96-104.

[30] Nonaka, I. and H. Takeuchi, The knowledge-creating company: How Japanese companies create the dynamics of innovation. 1995: Oxford university press.

[31] Smith, E. A., The role of tacit and explicit knowledge in the workplace. Journal of knowledge Management, 2001. 5 (4): p. 311-321.

[32] Ambrosini, V. and C. Bowman, Tacit knowledge: Some suggestions for operationalization. Journal of Management studies, 2001. 38 (6): p. 811-829. 
[33] Nonaka, I. and R. Toyama, The knowledge-creating theory revisited: knowledge creation as a synthesizing process. Knowledge management research \& practice, 2003. 1 (1): p. $2-10$.

[34] Panahi, S., J. Watson, and H. Patridge, Towards tacit knowledge sharing over social web tools. Journal of knowledge management, 2013. 17 (3).

[35] Hansen, M. T., N. Nohria, and T. Tierney, What's your strategy for managing knowledge. Harvard business review, 1999. 77 (2): p. 106-116.

[36] McMahon, C., A. Lowe, and S. Culley, Knowledge management in engineering design: personalization and codification. Journal of Engineering Design, 2004. 15 (4): p. 307-325.

[37] Cowan, R. and D. Foray, The economics of codification and the diffusion of knowledge. Industrial and corporate change, 1997. 6 (3): p. 595-622.

[38] Prencipe, A. and F. Tell, Inter-project learning: processes and outcomes of knowledge codification in project-based firms. Research policy, 2001. 30 (9): p. 1373-1394.

[39] Argote, L., Organizational learning: Creating, retaining and transferring knowledge. 2013, New York: Springer Science \& Business Media.

[40] Oliveira, M., Core competencies and the knowledge of the firm. Dynamic strategic resources: development, diffusion and integration, 1999: p. 17-42.

[41] Cabrilo, S. and S. Dahms, How strategic knowledge management drives intellectual capital to superior innovation and market performance. Journal of Knowledge Management, 2018.

[42] Kianto, A., et al., The interaction of intellectual capital assets and knowledge management practices in organizational value creation. Journal of Intellectual capital, 2014. 15 (3): p. 362-375.

[43] Shuhua, L., Knowledge Sharing: Interactive Processes Between Organizational Knowledge-Sharing Initiative and Individuals' Sharing Practice, in Building the Knowledge Society on the Internet: Sharing and Exchanging Knowledge in Networked Environments. 2008, IGI Global: Hershey, PA, USA. p. 1-23.

[44] Van den Hooff, B. and F. de Leeuw van Weenen, Committed to share: commitment and CMC use as antecedents of knowledge sharing. Knowledge and process management, 2004. 11 (1): p. 13-24.

[45] Lin, C. -P., To share or not to share: Modeling tacit knowledge sharing, its mediators and antecedents. Journal of business ethics, 2007. 70 (4): p. 411-428.

[46] Van Den Hooff, B. and J. A. De Ridder, Knowledge sharing in context: the influence of organizational commitment, communication climate and CMC use on knowledge sharing. Journal of knowledge management, 2004. 8 (6): p. 117-130.

[47] Dysvik, A., R. Buch, and B. Kuvaas, Knowledge donating and knowledge collecting: The moderating roles of social and economic LMX. Leadership \& Organization Development Journal, 2015. 36 (1): p. 35-53.

[48] Foss, N. J., et al., Encouraging knowledge sharing among employees: How job design matters. Human resource management, 2009. 48 (6): p. 871-893.
[49] Martín-de Castro, G., et al., The moderating role of innovation culture in the relationship between knowledge assets and product innovation. Technological Forecasting and Social Change, 2013. 80 (2): p. 351-363.

[50] Luthy, D. H. Intellectual capital and its measurement. in Proceedings of the Asian Pacific Interdisciplinary Research in Accounting Conference (APIRA), Osaka, Japan. 1998.

[51] Bontis, N., Intellectual capital: an exploratory study that develops measures and models. Management decision, 1998. 36 (2): p. 63-76.

[52] Chatzkel, J., Intellectual Capital. ExpressExec Innovation. 2002, Oxford, United Kingdom: John Wiley and Sons, Inc.

[53] Mayo, A., The role of employee development in the growth of intellectual capital. Personnel Review, 2000. 29 (4): p. 521533.

[54] Edvinsson, L. and M. S. Malone, Intellectual capital: Realizing your companyl's true value by finding its hidden brainpower. 1997.

[55] Bontis, N., S. Janošević, and V. Dženopoljac, Intellectual capital in Serbia's hotel industry. International Journal of Contemporary Hospitality Management, 2015. 27 (6): p. $1365-1384$.

[56] Carey, S., B. Lawson, and D. R. Krause, Social capital configuration, legal bonds and performance in buyer-supplier relationships. Journal of Operations Management, 2011. 29 (4): p. $277-288$.

[57] Gupta, A. K. and V. Govindarajan, Knowledge management's social dimension: Lessons from Nucor Steel. MIT Sloan Management Review, 2000. 42 (1): p. 71.

[58] Al-Alawi, A. I., N. Y. Al-Marzooqi, and Y. F. Mohammed, Organizational culture and knowledge sharing: critical success factors. Journal of knowledge management, 2007. 11 (2): p. 22-42.

[59] Herremans, I. M., et al., Intellectual capital and uncertainty of knowledge: control by design of the management system. Journal of business ethics, 2011. 98 (4): p. 627-640.

[60] Akbar, H., "Knowledge levels and their transformation: towards the integration of knowledge creation and individual learning”. Journal of Management Studies, 2003. 40 (8): p. $1997-2021$.

[61] Dewhurst, F. W. and J. G. Cegarra Navarro, External communities of practice and relational capital. The Learning Organization, 2004. 11 (4/5): p. 322-331.

[62] Wyatt, J. C., 10. Management of explicit and tacit knowledge. Journal of the Royal Society of Medicine, 2001. 94 (1): p. 6-9.

[63] Lai, J. -Y., C. -T. Wang, and C. -Y. Chou, How knowledge map fit and personalization affect success of KMS in hightech firms. Technovation, 2009. 29 (4): p. 313-324.

[64] Argote, L., Organizational learning: creating, retaining, and transferring knowledge. Kluwer Academic, 1999.

[65] Huysman, M. and D. De Wit, Practices of managing knowledge sharing: towards a second wave of knowledge management. Knowledge and process management, 2004. 11 (2): p. 81-92. 
[66] Helms, R., J. Cranefield, and J. v. Reijsen, Social Media and Knowledge Management: A Perfect Couple, in Social Knowledge Management in Action, R. Helms, J. Cranefield, and J. v. Reijsen, Editors. 2017, Springer International Publishing. p. 1-13.

[67] Hsu, I. C. and R. Sabherwal, From intellectual capital to firm performance: the mediating role of knowledge management capabilities. IEEE Transactions on Engineering Management, 2012. 58 (4): p. 626-642.

[68] Zhou, A. Z. and D. Fink, The intellectual capital web: a systematic linking of intellectual capital and knowledge management. Journal of intellectual capital, 2003. 4 (1): p. 3448.

[69] Hsu, I. -C., Knowledge sharing practices as a facilitating factor for improving organizational performance through human capital: A preliminary test. Expert Systems with applications, 2008. 35 (3): p. 1316-1326.

[70] Karagiannis, D., et al., A knowledge management approach for structural capital, in Practical Aspects of Knowledge Management, T. Yamaguchi, Editor. 2008. p. 135-146.

[71] Seleim, A., A. Ashour, and N. Bontis, Human capital and organizational performance: a study of Egyptian software companies. Management Decision 2007. 45 (4): p. 789-801.

[72] Edvinsson, L. and P. Sullivan, Developing a model for managing intellectual capital. European management journal, 1996. 14 (4): p. 356-364.

[73] Egbu, C. O., Managing knowledge and intellectual capital for improved organizational innovations in the construction industry: an examination of critical success factors. Engineering, Construction and Architectural Management, 2004. 11 (5): p. 301-315.

[74] Moran, P., "Structural vs. relational embeddedness: social capital and managerial performance". Strategic Management Journal, 2005. 26 (12): p. 1129 - 1151.

[75] Mehralian, G., J. A. Nazari, and P. Ghasemzadeh, The effects of knowledge creation process on organizational performance using the BSC approach: the mediating role of intellectual capital. Journal of Knowledge Management, 2018.

[76] Radaelli, G., et al., Intellectual capital and knowledge sharing: the mediating role of organisational knowledge-sharing climate. Knowledge Management Research \& Practice, 2011. 9 (4): p. 342-352.

[77] Liao, S. -H., W. -C. Fei, and C. -C. Chen, Knowledge sharing, absorptive capacity, and innovation capability: an empirical study of Taiwan's knowledge-intensive industries. Journal of information science, 2007. 33 (3): p. 340-359.

[78] Holste, J. S. and D. Fields, Trust and tacit knowledge sharing and use. Journal of knowledge management, 2010. 14 (1): p. 128-140.

[79] Bueno, E., et al., Tangible slack versus intangible resources: the influence of technology slack and tacit knowledge on the capability of organisational learning to generate innovation and performance. International Journal of Technology Management, 2010. 49 (4): p. 314-337.

[80] Chaminade, C. and U. Johanson, Can guidelines for intellectual capital management and reporting be considered without addressing cultural differences? Journal of Intellectual Capital, 2003.4 (4): p. 528-542.

[81] Martín-de-Castro, G., et al., Towards 'an intellectual capitalbased view of the firm': origins and nature. Journal of Business Ethics, 2011.98 (4): p. 649-662.

[82] Sánchez-Canizares, S. M., M. Ángel Ayuso Muñoz, and T. López-Guzmán, Organizational culture and intellectual capital: a new model. Journal of intellectual capital, 2007. 8 (3): p. 409-430.

[83] Nazari, J. A., et al., Organizational culture, climate and IC: an interaction analysis. Journal of Intellectual Capital, 2011. 12 (2): p. 224-248.

[84] Lee, I. -C., C. Y. Lin, and T. -Y. Lin, The creation of national intellectual capital from the perspective of Hofstede's national culture. Journal of Intellectual Capital, 2017. 18 (4): p. $807-$ 831.

[85] Angel Axtle Ortiz, M., Analysis and valuation of intellectual capital according to its context. Journal of Intellectual Capital, 2009. 10 (3): p. 451-482.

[86] Andriessen, D. and M. van den Boom, East is East, and West is West, and (n) ever its intellectual capital shall meet. Journal of Intellectual capital, 2007. 8 (4): p. 641-652. 